\title{
Outcomes of saline implant-based immediate breast reconstruction: 15-year follow-up results
}

\author{
Kyunghyun Min ${ }^{1}$, Dong Nyeok \\ Jeon $^{1}$, Eun Jeong Choi ${ }^{2}$, Taik Jong \\ Lee $^{3}$, Jin Sup Eom ${ }^{1}$, Hyun Ho \\ Han $^{1}$, Eun Key Kim ${ }^{1}$ \\ ${ }^{1}$ Department of Plastic Surgery, Asan \\ Medical Center, University of Ulsan \\ College of Medicine, Seoul; ${ }^{2}$ The Way \\ Plastic Surgery Clinic, Seoul; ${ }^{3}$ Department \\ of Plastic Surgery, Hongcheon Asan \\ Hospital, Hongcheon, Korea
}

Background Although rarely used at present in South Korea, saline implants accounted for most of the implants used from 1992 to 2007. However, few studies have reported on the long-term outcomes of saline implants, especially in breast reconstruction. We analyzed the long-term outcomes of patients who underwent direct-to-saline implant reconstruction.

Methods This retrospective study included patients who underwent saline implantbased immediate breast reconstruction between 2003 and 2007. The patients' demographic information, medical history, operative/implant details, and oncologic data were collected. Early and late complications, reoperations, and final outcomes of the implant (maintenance, explantation, exchange, and autologous conversion) were analyzed to determine the long-term results and to identify factors affecting the outcomes.

Results Early complications (within 90 days) were noted in $19.5 \%$ of patients and late complications (after 90 days) occurred in $29.3 \%$ of patients. The most common early complications were skin necrosis and delayed healing, whereas the most common late complications were rippling or visibility and capsular contracture. Of the implants, $22 \%$ were replaced (12\%) or converted to autologous tissue (10\%). The factors that influenced the final outcomes were patient age, nipple-areola-sparing procedure, breast size, implant fill volume, and implant manufacturer.

Conclusions Patients who previously received saline implants still visit the clinic for consultations. This long-term follow-up study with few dropouts reflects the real needs of reconstruction patients. Our results provide useful information for consulting with patients who already have saline implants or those who request for as much information about available implant options as possible.

Keywords Breast implants / Complications / Implant capsular contracture / Mastectomy, subcutaneous
We sincerely thank Professor Jung-Bok Lee, Division of Biostatistics, Center for Medical Research and Information, Asan Medical Center, University of Ulsan College of Medicine, for support with the statistical analysis and professional advice.

\section{INTRODUCTION}

Received: Jul 15, 2020 Revised: Aug 7, 2020 Accepted: Aug 10, 2020 Correspondence: Eun Key Kim Department of Plastic Surgery, Asan Medical Center, University of Ulsan College of Medicine, 88 Olympic-ro 43-gil, Songpa-gu, Seoul 05505, Korea

Tel: +82-2-3010-3600, Fax: +82-2-476-7471, E-mail: nicekek@korea.com

Copyright @ 2020 The Korean Society for Aesthetic Plastic Surgery.

This is an Open Access article distributed under the terms of the Creative Commons Attribution Non-Commercial License (https://creativecommons.org/licenses/by-nc/4.0/) which permits unrestricted non-commercial use, distribution, and reproduction in any medium, provided the original work is properly cited. www.e-aaps.org
Since Czerny reported the first successful breast augmentation by transplanting a lipoma from the trunk to the breast in a patient after partial mastectomy, the use of a wide variety of alloplastic materials has been attempted, such as polyurethane, polytetrafluoroethylene (Teflon), and expanded polyvinyl alcohol formaldehyde (Ivalon sponge), ultimately leading to considerable morbidity. Various other materials have also been injected into the breast parenchyma, including epoxy resin, paraffin, petroleum jelly, and liquid silicone [1,2]. 
The application of modern breast implants as a two-component prosthesis with a shell and gel filler started in 1962, when Cronin and Gerow used silicone gel as a filling material contained within a thin, smooth silicone elastomer shell [3]. Meanwhile, the use of inflatable saline-filled implants to enable a smaller incision was first reported in 1965 [4]. Slight overfilling was recommended to achieve better durability, but led to an unnatural spherical shape, firmness, and scalloping along the implant edge. The consistency was similar to that of water instead of natural breast tissue. Therefore, efforts to develop an implant with a more natural shape and feeling were continued. The first-generation commercial silicone implant by Cronin and Brauer (manufactured by Dow Corning Corp.) contained a thick two-piece silicone elastomer shell with a seam along the periphery. These early implants had a high contracture rate, which encouraged the development of second-generation implants with a thinner, seamless shell with less viscous silicone gel filling. However, the second-generation implants had the drawbacks of gel bleeding and sticky residue within the capsule. Hence, the development of third-generation silicone implants in the 1980s focused on improving implant strength and reducing gel bleeding and implant rupture.

However, the United States Food and Drug Administration (US FDA) called for the temporary restriction of third-generation implants from the market in 1992, stating that there was inadequate information to demonstrate the safety and effectiveness of breast implants. Although medical access to silicone implants continued for selected clinical studies, and the development of fourth- and fifth-generation implants continued, saline-filled breast implants were the only approved implants that most physicians and patients could access until 2006, when the US FDA finally lifted its restrictions on silicone breast implants. Moreover, in Korea, saline implants were the only accessible implants from 1992 to July 2007.

Large-scale follow-up data on silicone implants were published thereafter, and several studies compared the performance, quality of life, satisfaction, and cost-effectiveness of silicone and saline implants [5-8]. However, fewer reports in the literature could be found on the performance and long-term outcomes of saline implants than on those of silicone implants. Clinical surveillance and complication analyses may be less extensive for saline implants because of the perception that they are "safer" than silicone implants. Less attention has also been paid to research and development for newer-generation saline implants after the introduction of formstable silicone implants. Although it is difficult to determine the exact number of implantations in Korea, it is speculated that many patients underwent breast augmentations and reconstructions with saline implants during the silicone implant moratorium. However, few studies related to saline implants have been published, and only one of them reported long-term outcomes [9-13].

Many patients with saline implants do not seek follow-up implant-related medical care unless they notice deflation of the im- plant. However, increasing health concerns and press reports of breast implant-associated anaplastic large-cell lymphoma in Korea have raised awareness about the safety and prognosis of breast prostheses of any kind. We aimed to analyze the outcomes of direct-to-implant reconstruction with saline implants between 2003 and 2007 to determine the long-term results and to identify factors affecting the outcomes.

\section{METHODS}

This retrospective study included patients who underwent implant-based immediate breast reconstruction with saline implants between May 2003 and March 2007. All patients who were followed up until September 2018 were considered eligible. This study was approved by the institutional review board of the hospital (approval No. 2018-0540).

The patients' demographic information, such as age, body mass index, underlying diseases, and lifestyle variables, including smoking history, was retrieved through a review of their medical records. Operative details (mastectomy specimen weight, implant fill volume, mastectomy technique, lymph node dissection) and oncologic data (cancer stage, preoperative and postoperative adjuvant therapies, subsequent recurrence and management) were also investigated.

Early and late complications, reoperations, and final outcomes of the implants were analyzed. An early complication was defined as any complication that occurred within 90 days after the operation, including infection, delayed wound healing, mastectomy flap skin necrosis, seroma, hematoma, wound dehiscence, and implant exposure. A late complication was defined as any complication that was observed 90 days after the operation, including late infection, late seroma, deflation, malposition, capsular contracture $\geq$ grade 3 , unimproved pain, animation, thinning, and rippling or visibility. The final outcome of the implant was categorized as maintenance, explantation, implant change, and autologous (flap) conversion.

Variables were analyzed using the independent $t$-test or MannWhitney test and the chi-square test or Fisher exact test for continuous and categorical variables, respectively. The impact of demographic and perioperative variables on complications and outcomes was analyzed for each implant type. Owing to the small sample size, significance was defined as $\mathrm{P}<0.1$. The statistical analysis was performed using SPSS 24.0 (IBM Corp., Armonk, NY, USA).

\section{RESULTS}

A total of 37 patients underwent breast reconstruction with a saline implant in 41 breasts. All implants had a smooth-shell surface. The average age was $34.54 \pm 7.99$ years (range, $23-53$ years) and the average body mass index was $19.68 \pm 2.16 \mathrm{~kg} / \mathrm{m}^{2}$ (range, 16.3-24.3 
Table 1. Patients' general demographic characteristics

\begin{tabular}{lc}
\hline Variable & Patient $(\mathrm{n}=37)$ \\
\hline Age lyr) & $34.54 \pm 7.99$ \\
Body mass index $\left(\mathrm{kg} / \mathrm{m}^{2}\right)$ & $19.68 \pm 2.16$ \\
Smoking history & $3(8.11)$ \\
Diabetes mellitus & 0 \\
Hypertension & $1(2.70)$ \\
Pregnancy history & $17(45.95)$ \\
Mean follow-up period (mo) & $127.03 \pm 43.15$ \\
\hline
\end{tabular}

Values are presented as mean \pm SD or number $(\%)$.

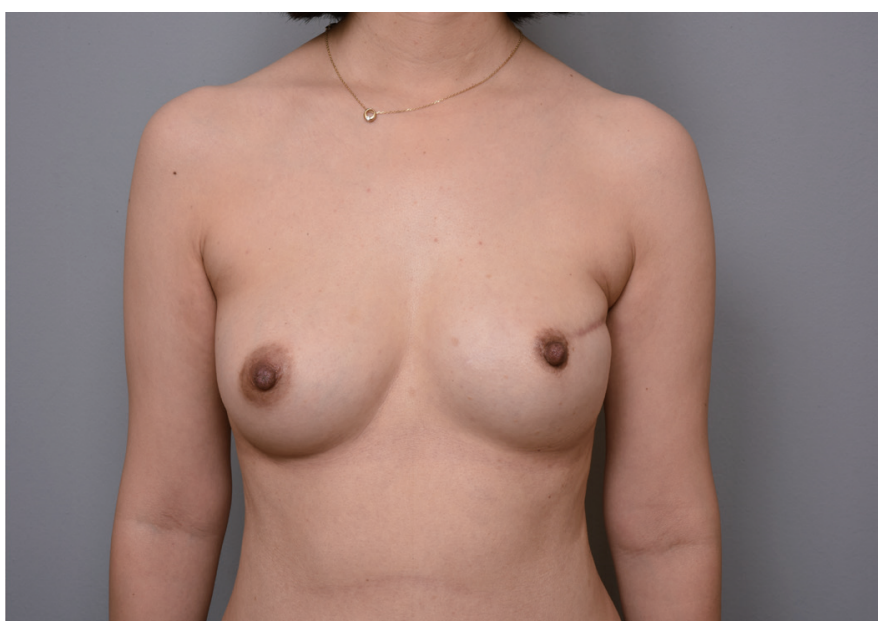

Fig. 1. A 28-year-old woman was diagnosed with breast cancer in her left breast. After nipple-sparing mastectomy, the mastectomy specimen weighed $340 \mathrm{~g}$. A $325-\mathrm{mL}$ Mentor saline implant was inserted. The photograph was taken 172 months after the reconstruction. The implant maintained a favorable aesthetic outcome without signs of rupture.

$\mathrm{kg} / \mathrm{m}^{2}$ ). Three patients $(8.11 \%)$ had a smoking history and one patient $(2.70 \%)$ had a history of hypertension. None of the patients were diagnosed with diabetes, and 17 patients (45.95\%) had a history of pregnancy. The average follow-up period was $127.03 \pm 43.15$ months (range, 16-175 months) (Table 1).

Mastectomy was performed on the right side in 24 cases (58.54\%) and on the left side in 17 cases (41.46\%), and nipplesparing mastectomy was performed in 27 breasts $(65.85 \%)$. The average mastectomy specimen weight was $289.12 \pm 129.13 \mathrm{~g}$ (range, $75-555 \mathrm{~g}$ ) and the average fill volume of the saline implants was $232.44 \pm 53.98 \mathrm{~cm}^{3}$ (range, $130-350 \mathrm{~cm}^{3}$ ). Sentinel lymph node biopsy or axillary lymph node dissection was performed in 23 cases (56.1\%), and contralateral augmentation was performed in three patients. Implants manufactured by Allergan (Allergan Inc., Irvine, CA, USA) were used in 11 cases (26.83\%) and implants manufactured by Mentor (Mentor Corp., Santa Barbara, CA, USA) were used in 26 cases (73.17\%) (Table 2, Fig. 1).
Table 2. Surgical details

\begin{tabular}{lc}
\hline Variable & Implants \\
\hline Reconstruction side & $24(58.54)$ \\
Right & $17(41.46)$ \\
Left & \\
Mastectomy type & $27(65.85)$ \\
Nipple-sparing & $14(34.15)$ \\
Skin-sparing & $289.12 \pm 129.13$ \\
Mastectomy weight (g) & $232.44 \pm 53.98$ \\
Implant fill volume (cm $\left.{ }^{3}\right)$ & \\
Lymph node dissection & $18(43.90)$ \\
None & $12(29.27)$ \\
Sentinel node & $11(26.83)$ \\
Axillary node & \\
Previous operation & $36(87.8)$ \\
None & $3(7.32)$ \\
Benign mass excision & $2(4.88)$ \\
Breast-conserving operation with radiotherapy & $4(9.76)$ \\
Bilateral reconstruction & $3(7.32)$ \\
Contralateral augmentation & $3(7.32)$ \\
Implant manufacturer & $1(2.44)$ \\
Allergan & $11(26.83)$ \\
Mentor & $30(73.17)$ \\
Reve of ADM & \\
\hline & \\
Revisionary surgery & \\
\hline
\end{tabular}

Values are presented as number $(\%)$ or mean \pm SD. ADM, acellular dermal matrix.

Twenty-one patients were diagnosed with stage 1 cancer (51.22\%) and $10(24.39 \%)$ were diagnosed with carcinoma in situ. Neoadjuvant chemotherapy was performed in two cases $(4.88 \%)$ and adjuvant chemotherapy was performed in 15 cases (36.59\%). Two patients $(4.88 \%)$ were treated with breast-conserving surgery and radiation therapy before implant insertion, and postoperative radiotherapy was performed in three cases (7.32\%). During the followup period, local recurrence occurred in five cases $(12.2 \%)$ and regional lymph node recurrence took place in three cases $(7.32 \%)$ (Table 3).

The total number of early complications was eight, including three cases of skin necrosis (7.32\%), one case of hematoma (2.44\%), and one case (2.44\%) of implant exposure due to delayed wound healing, which occurred within 90 days after the operation. Late complications occurred in 12 cases (29.27\%). The most frequent late complication was rippling or visibility (six cases, 14.64\%), and there were no cases of infection, seroma, or deflation. In addition, capsular contracture $\geq$ grade 3 (five cases, 12.20\%), malposition (four cases, 9.76\%), pain (two cases, $4.88 \%$ ), and thinning (one case, $2.44 \%$ ) were reported as common chief complaints. Nine of 
Table 3. Oncologic information

\begin{tabular}{lc}
\hline Variable & No. of implants (\%) \\
\hline Perioperative & \\
Stage & $10(24.39)$ \\
In situ & $21(51.22)$ \\
1 & $7(17.07)$ \\
2 & $3(7.32)$ \\
3 & $2(4.88)$ \\
Neoadjuvant chemotherapy & $15(36.59)$ \\
Adjuvant chemotherapy & $2(4.88)$ \\
Preoperative radiotherapy & $3(7.32)$ \\
Adjuvant radiotherapy & $19(46.34)$ \\
Hormone therapy & \\
Follow-up & $5(12.20)$ \\
Local recurrence & $3(7.32)$ \\
Regional (lymph node) recurrence & \\
No. of operations for recurrence & $36(87.8)$ \\
0 & $3(7.32)$ \\
1 & $2(4.88)$ \\
2 & 0 \\
Implant removal owing to recurrence & \\
\hline
\end{tabular}

Table 5. Subgroup comparison: early complications within postoperative 90 days

\begin{tabular}{lccc}
\hline Variable & $\begin{array}{c}\text { No } \\
\text { complications } \\
(\mathrm{n}=33)\end{array}$ & $\begin{array}{c}\text { Any } \\
\text { complications } \\
(\mathrm{n}=8)\end{array}$ & P-value \\
\hline Age lyr) & $36.76 \pm 9.19$ & $31.63 \pm 4.69$ & 0.1362 \\
Body mass index $\left(\mathrm{kg} / \mathrm{m}^{2}\right)$ & $19.77 \pm 2.05$ & $19.61 \pm 2.39$ & 0.8486 \\
History of pregnancy & $16(48.48)$ & $3(37.5)$ & 0.7033 \\
Hormone therapy & $14(42.42)$ & $5(62.5)$ & 0.4362 \\
Previous surgery history & $4(12.12)$ & $1(12.5)$ & 1.0000 \\
Stage 2 or 3 & $7(21.21)$ & $3(37.5)$ & 0.3780 \\
Skin-sparing mastectomy & $14(42.42)$ & 0 & $0.0353^{\text {a) }}$ \\
Any lymph node dissection & $18(54.55)$ & $5(62.5)$ & 1.0000 \\
Implant manufacturer: Allergan & $8(24.24)$ & $3(37.5)$ & 0.6582 \\
Mastectomy specimen weight (g) & $282.7 \pm 127.81$ & $315.63 \pm 140.01$ & 0.5646 \\
Implant fill volume $\left(\mathrm{cm}^{3}\right)$ & $232.12 \pm 51.16$ & $233.75 \pm 68.44$ & 0.9605 \\
\hline
\end{tabular}

Values are presented as mean \pm SD or number $(\%)$.

${ }^{a l} P<0.1$.

the 41 saline implants were eventually removed. Five implants were exchanged with another implant (12.20\%) and four were converted to autologous tissue (9.76\%) (Table 4).

When a two-subgroup comparison was conducted according to the occurrence of early complications (within 90 days), skin-sparing mastectomy (vs. nipple-areolar skin-sparing mastectomy) was significantly more common in the group without early complica-
Table 4. Early/late complications and final results

\begin{tabular}{|c|c|}
\hline Variable & No. of implants $(\%)$ \\
\hline \multicolumn{2}{|l|}{ Early complications } \\
\hline Any complications within postoperative 90 days & $8(19.51)$ \\
\hline Infection & 0 \\
\hline Red breast syndrome & 0 \\
\hline Skin necrosis & $3(7.32)$ \\
\hline Delayed wound healing & $5(12.20)$ \\
\hline Seroma & 0 \\
\hline Hematoma & $1(2.44)$ \\
\hline Dehiscence & 0 \\
\hline Implant exposure & $1(2.44)$ \\
\hline \multicolumn{2}{|l|}{ Late complications } \\
\hline Any complications after postoperative 90 day & 12 (29.27) \\
\hline Infection & 0 \\
\hline Seroma & 0 \\
\hline Deflation & 0 \\
\hline Malposition & $4(9.76)$ \\
\hline Capsular contracture $\geq$ grade 3 & $5(12.20)$ \\
\hline Pain & $2(4.88)$ \\
\hline Animation & 0 \\
\hline Thinning & $1(2.44)$ \\
\hline Rippling or visibility & $6(14.63)$ \\
\hline \multicolumn{2}{|l|}{ Final outcome } \\
\hline Maintenance & $32(78.05)$ \\
\hline Implant change & $5(12.20)$ \\
\hline Autologous conversion & $4(9.76)$ \\
\hline
\end{tabular}

tions (42.42\% vs. $0 \%, \mathrm{P}=0.0353$ ) (Table 5). Meanwhile, patients with late complications were significantly older than those without late complications (32.66 years vs. 43.25 years, $\mathrm{P}=0.0001$ ). Notably, Allergan implants were significantly associated with late complications, as $50 \%$ of the implants with complications were made by $\mathrm{Al}$ lergan, whereas only $17 \%$ of the implants without complications were Allergan $(\mathrm{P}=0.0522)$. Implant fill volume also significantly affected the occurrence of late complications $\left(258.33 \pm 45.49 \mathrm{~cm}^{3}\right.$ in the group with complications vs. $221.72 \pm 54.25 \mathrm{~cm}^{3}$ in the group without complications, $\mathrm{P}=0.0427$ ) (Table 6).

Lastly, the final outcomes of the implants were analyzed. Patients whose implants were removed were older (42.44 \pm 10.47 years vs. $33.88 \pm 7.26$ years, $\mathrm{P}=0.0073)$ and were more likely to have an $\mathrm{Al}$ lergan prothesis $(66.67 \%$ vs. $15.63 \%, \mathrm{P}=0.0058)$. In addition, the mastectomy specimen was heavier $(363.78 \pm 128.77 \mathrm{~g}$ vs. $268.13 \pm$ $123.14 \mathrm{~g}, \mathrm{P}=0.0630)$ and the implant fill volume was larger $(268.89 \pm$ $36.55 \mathrm{~cm}^{3}$ vs. $\left.222.19 \pm 54.05 \mathrm{~cm}^{3}, \mathrm{P}=0.0157\right)$ in the implant removal group (Table 7). Local recurrence occurred in five cases, which were all indicated for oncologic surgery. All implants were maintained despite local recurrence and subsequent wide excision. 
Table 6. Subgroup comparison: late complications after postoperative 90 days

\begin{tabular}{lccc}
\hline Variable & $\begin{array}{c}\text { No } \\
\text { complication } \\
(\mathbf{n}=29)\end{array}$ & $\begin{array}{c}\text { Any } \\
\text { complications } \\
(\mathrm{n}=12)\end{array}$ & P-value \\
\hline Age (yr) & $32.66 \pm 6.16$ & $43.25 \pm 9.59$ & $0.0001^{\text {a) }}$ \\
Body mass index $\left(\mathrm{kg} / \mathrm{m}^{2}\right)$ & $19.54 \pm 2.00$ & $20.33 \pm 2.36$ & 0.3086 \\
History of pregnancy & $12(41.38)$ & $7(58.33)$ & 0.3219 \\
Hormone therapy & $14(48.28)$ & $5(41.67)$ & 0.6994 \\
Previous surgery history & $5(17.24)$ & 0 & 0.2979 \\
Stage 2 or 3 & $6(20.69)$ & $4(33.33)$ & 0.4410 \\
Skin-sparing mastectomy & $13(44.83)$ & $1(8.33)$ & $0.0328^{\text {a) }}$ \\
Any lymph node dissection & $17(58.62)$ & $6(50.0)$ & 0.6128 \\
Implant manufacturer: Allergan & $5(17.24)$ & $6(50.0)$ & $0.0522^{\text {a) }}$ \\
Mastectomy specimen weight (g) & $270.17 \pm 126.51$ & $334.92 \pm 129.07$ & 0.1518 \\
Implant fill volume $\left(\mathrm{cm}^{3}\right)$ & $221.72 \pm 54.25$ & $258.33 \pm 45.49$ & $0.0427^{\text {a) }}$ \\
Early complications within & $7(24.14)$ & $1(8.33)$ & 0.3984 \\
$\quad$ postoperative 90 days & & & \\
\hline
\end{tabular}

Values are presented as mean \pm SD or number $(\%)$.

${ }^{\text {al }} \mathrm{P}<0.1$.

\section{DISCUSSION}

The use of silicone implants rapidly increased after the US FDA lifted its restrictions, and most aesthetic and reconstructive procedures are currently performed with silicone implants. Especially in postmastectomy breast reconstruction, previous cross-sectional studies showed that patients who received silicone implants reported significantly higher satisfaction and higher quality-of-life scores as measured by the BREAST-Q than those who received saline implants [6,14]. A thorough analysis of the US FDA large postapproval study database was reported in 2019, which enrolled over 90,000 women who received a saline implant or a silicone implant from two manufacturers (Allergan and Mentor) from 2007 to 2010. This prospective cohort study revealed that silicone implants were associated with higher rates of Sjögren syndrome, scleroderma, rheumatoid arthritis, and other morbidities. The rate of rupture was higher for saline implants, and that of capsular contracture was higher for silicone implants. The reoperation rate was $11.7 \%$ for primary augmentation and $25 \%$ for primary/revision reconstruction at 7 years, which is similar to our reoperation rate (22\%) [8].

According to a business report, silicone implants predominated in the United States, with an $>80 \%$ market share when implants were categorized by the filler material type. However, the proportion of saline implant usage for augmentation/reconstruction cases in 2018 to 2019 remained at about 18\% in the United States and 4\% in Korea for the Mentor implant (data not shown). Siotos et al. [7] reported that $43 \%$ of their patients underwent breast reconstruc-
Table 7. Subgroup comparison: final outcomes

\begin{tabular}{|c|c|c|c|}
\hline Variable & $\begin{array}{l}\text { Implant } \\
\text { removal } \\
(n=9)\end{array}$ & $\begin{array}{c}\text { Implant } \\
\text { maintenance } \\
(n=32)\end{array}$ & P-value \\
\hline Age (yr) & $42.44 \pm 10.47$ & $33.88 \pm 7.26$ & $0.0073^{\mathrm{al}}$ \\
\hline Body mass index $\left(\mathrm{kg} / \mathrm{m}^{2}\right)$ & $20.06 \pm 2.33$ & $19.65 \pm 2.05$ & 0.6139 \\
\hline History of pregnancy & $4(44.44)$ & 15 (46.88) & 1.0000 \\
\hline Hormone therapy & $4(44.44)$ & $15(46.88)$ & 1.0000 \\
\hline Previous surgery history & 0 & 5 (15.63) & 0.5681 \\
\hline Stage 2 or 3 & 3 (33.33) & 7 (21.88) & 0.6622 \\
\hline Skin-sparing mastectomy & $1(11.11)$ & 13 (40.63) & 0.1308 \\
\hline Any lymph node dissection & $5(55.56)$ & 18 (56.25) & 1.0000 \\
\hline $\begin{array}{l}\text { Implant manufacturer: } \\
\text { Allergan }\end{array}$ & $6(66.67)$ & 5 (15.63) & $0.0058^{\mathrm{al}}$ \\
\hline $\begin{array}{l}\text { Mastectomy specimen } \\
\text { weight (g) }\end{array}$ & $363.78 \pm 128.77$ & $268.13 \pm 123.14$ & $0.0630^{\mathrm{al}}$ \\
\hline Implant fill volume $\left(\mathrm{cm}^{3}\right)$ & $268.89 \pm 36.55$ & $222.19 \pm 54.05$ & $0.0157^{\mathrm{al}}$ \\
\hline $\begin{array}{l}\text { Early complications within } \\
\text { postoperative } 90 \text { days }\end{array}$ & $1(11.11)$ & $7(21.88)$ & 0.6586 \\
\hline $\begin{array}{c}\text { Late complications after } \\
\text { postoperative } 90 \text { days }\end{array}$ & 0 & 5 (15.63) & 0.5681 \\
\hline
\end{tabular}

Values are presented as mean \pm SD or number $(\%)$.

${ }^{a l} P<0.1$.

tion with a saline implant between 2010 and 2015. The BREASTQ-adjusted life-years were 28.11 for saline implants and 23.57 for silicone implants, demonstrating the higher cost-effectiveness of saline implants. The authors suggested that saline implants may be more cost-effective than silicone implants, although the difference was small. The merits and demerits of each implant are clear. Saline implants were never as controversial as silicone gel implants; however, they also have not yielded the same innovations. Several shaped saline implants are now available, although if the main concern is shape and feel, silicone implants would be a better option. If safety and a minimal or remote incision are prioritized, saline implants may be a better choice [15].

With respect to the outcomes of saline implants, deflation, capsular contracture, and consequent distortion of breast shape were common causes of implant removal. Gutowski et al. [16] reported a reoperation rate of 20.6\% (104 of 504 patients) between 1980 and 1989. Of these, Implant deflation occurred in $5.5 \%$ and significant capsular contracture affected $20.4 \%$ of patients, necessitating open capsulectomy for capsular contracture and removal or replacement of a deflated implant. A longer follow-up report by Cunningham et al. [17] revealed an overall complication rate of $20.2 \%$, with a reoperation rate for capsular contracture or deflation of $23.1 \%$.

From a prospective multicenter study of $>900$ augmentation or reconstruction patients implanted with Natrelle saline breast implants, the 10-year risk rate for implant replacement/removal was $20.2 \%$ and $39.5 \%$ for augmentation and reconstruction patients, 
respectively. The most common reason for implant replacement/ removal among augmentation patients was the patient's choice for a style or size change, whereas that among reconstruction patients was deflation [18]. In reconstruction cases, a previous report involving 201 Korean patients showed a deflation rate of $9.4 \%$, and three of the 19 patients with deflation had iatrogenic causes. Deflation was more common in textured implants, and significant capsular contracture was reported in $17 \%$ [9].

Although our study included fewer patients than previous studies, we analyzed the long-term outcomes of saline implants and the factors affecting those outcomes over a longer follow-up period. The most common early complications were delayed wound healing $(12.2 \%)$ and skin necrosis (7.3\%), and the common late complications were rippling or visibility (14.6\%) and capsular contracture (12.2\%). A significant factor influencing early complications was nipple-areola-sparing mastectomy, which seemed to be directly associated with delayed wound healing and skin necrosis. The nipple-areola-sparing technique in the past would have been performed more often by less-experienced surgeons than in the present, which may have resulted in longer operation times and more intense skin traction.

Late complications were defined as those that occurred $>90$ days postoperatively; their incidence was mainly documented from patient-reported complaints and were often associated with reoperation. The factors influencing late complications were the nippleareola-sparing technique, patient age, implant fill volume, and implant manufacturer. We assumed that early skin necrosis due to the nipple-areola-sparing procedure would have led to skin contraction or early reoperation, which subsequently would have influenced later shape distortion. The size of the implant has often been reported to be associated with the final outcome; correspondingly, our results did not show a correlation of implant size with early complications (within 90 days), but did show a correlation with late complications (after 90 days). The impact of patient age on late complications and reoperations may be partly explained by the larger implant size in older patients or by asymmetry due to breast ptosis. Another explanation may be the different oncologic status of the patients (the younger the patient, the higher the likelihood of advanced cancer). Oncologic seriousness and the requirement for reoperations due to recurrence often diminished patients' interest in aesthetics.

With respect to the manufacturer, the incidence of late complications was significantly higher for Allergan implants than for Mentor implants. As all our saline implants were smooth round implants, we do not think that this factor was directly related to the high rate of performance failure of Biocell implants, as reported in a recent article that analyzed breast implant explantations and found that Biocell implants were associated with double capsule, late seroma, and pain [19]. Conversely, our results showed that the explanted Allergan implants were more often associated with rip- pling, visibility, thinning, and/or pain, whereas two of the four Mentor implants were explanted because of malposition.

The absence of prosthesis removal or lack of reoperation in patients with tumor recurrence does not inherently mean that the outcomes, despite tumor ablative operations and radiotherapy because of recurrence, were good. The treatment of patients after breast reconstruction often involves multidisciplinary modalities, including oncologic surgery, oncology, radiation oncology, gynecology/endocrinology, and rehabilitation. Oncologic severity and adjuvant therapies may diminish patients' interest in aesthetic outcomes. The late aesthetic outcomes in the current retrospective study mainly depended on the patients' voluntary and subjective requests, which may explain the lower late elective complication rate in our study than has been reported in the literature. Another point to consider is that direct-to-implant reconstruction was significantly less common than at present. The fewer number of overall reconstructions meant that more autologous reconstructions were performed, and far more strict patient selection criteria were applied for direct-to-implant cases, such as younger age, smaller breasts with less ptosis, and lower clinical cancer stage (less likelihood for adjuvant radiation). This may also explain the lower rate of both early and late complications.

The study has some limitations. Firstly, the sample size is small, and this is not a case-control study. Nevertheless, this study presents the results of long-term follow-up with few dropouts that reflect the real needs of reconstruction patients. Although the use of saline implants is rare in Korea at present, with saline implants having a $<4 \%$ market share, patients who received saline implants in the past still visit the clinic for consultations. The use of textured anatomic silicone implants has been abruptly discontinued for unexpected reasons, and saline implants may not simply be considered as an obsolete option. Therefore, this study provides useful information for consulting with patients who already have saline implants or those who request information about as many implant options as possible.

Another limitation is that onset of late complications was not classified by the period. Early information on reconstructed patients was collected on paper charts, so some visits due to late complications were not recorded. In addition, the choice of implant was based on each patient's breast width and projection; therefore, no difference in patient characteristics was found according to whether an Allergan or Mentor implant was inserted. Nonetheless, there might be a hidden disturbance variable.

In summary, patients who underwent direct-to-saline implant reconstruction showed an initial complication (within 90 days) rate of $19.5 \%$ and a late complication (after 90 days) rate of $29.3 \%$. The most common initial complications were skin necrosis and delayed healing, and the most common late complications were rippling or visibility and capsular contracture. Late complications may have been underestimated because they were mainly based on 
patient-reported complaints. Approximately $22 \%$ of the implants were replaced $(12 \%)$ or converted to autologous tissue (10\%). The factors that influenced the final outcomes were patient age, a nipple-areola-sparing procedure, breast size and implant fill volume, and implant manufacturer.

\section{NOTES}

\section{Conflict of interest}

No potential conflict of interest relevant to this article was reported.

\section{Ethical approval}

The study was approved by the Institutional Review Board of Asan Medical Center Hospital (IRB No. 2018-0540) and performed in accordance with the principles of the Declaration of Helsinki.

\section{Patient consent}

The patient provided written informed consent for the publication and the use of her image.

\section{ORCID}

Kyunghyun Min https://orcid.org/0000-0002-7807-0143 Dong Nyeok Jeon https://orcid.org/0000-0002-6252-1261 Eun Jeong Choi https://orcid.org/0000-0002-6392-947X Taik Jong Lee https://orcid.org/0000-0003-3929-7289 Jin Sup Eom Hyun Ho Han https://orcid.org/0000-0003-3229-2012 https://orcid.org/0000-0001-7072-9882

Eun Key Kim

\section{REFERENCES}

1. Maxwell GP, Gabriel A. The evolution of breast implants. Plast Reconstr Surg 2014;134:12S-17S.

2. Czerny V. Plastic replacement of the breast with a lipoma. Chir Kong Verhandl 1895;2:216.

3. Cronin TD, Brauer RO. Augmentation mammaplasty. Surg Clin North Am 1971;51:441-52.

4. Maxwell GP, Gabriel A. The evolution of breast implants. Clin Plast Surg 2009;36:1-13.

5. Picha GJ, Singh N, Murphy DK. Natrelle silicone breast implant follow-up study: demographics, lifestyle, and surgical characteristics of

more than 5000 reconstruction subjects. Plast Reconstr Surg Glob Open 2015;3:e489.

6. McCarthy CM, Klassen AF, Cano SJ, et al. Patient satisfaction with postmastectomy breast reconstruction: a comparison of saline and silicone implants. Cancer 2010;116:5584-91.

7. Siotos C, Sarmiento S, McColl M, et al. Cost-effectiveness analysis of silicone versus saline implant-based breast reconstruction using the BREAST-Q. Plast Reconstr Surg 2019;143:276e-284e.

8. Coroneos CJ, Selber JC, Offodile AC 2nd, et al. US FDA breast implant postapproval studies: long-term outcomes in 99,993 patients. Ann Surg 2019;269:30-6.

9. Kim IK, Lee JH, Kim YH, et al. Clinical durability and deflation of saline-filled breast implant in breast reconstruction. J Korean Soc Plast Reconstr Surg 2011;38:808-14.

10. Hwang $\mathrm{CH}$, Kim EK, Eom JS, et al. Immediate breast reconstruction using saline implant: extension of pectoralis major muscle coverage with AlloDerm(R). J Korean Soc Plast Reconstr Surg 2009;36:161-6.

11. Yoon W. Reoperative augmentation mammoplasty of saline implants with cohesive silicone gel implants: a personal review. J Korean Soc Aesthetic Plast Surg 2009;15:18-23.

12. Lee SD. Breast reconstruction using saline implants in a woman with Poland syndrome. J Korean Surg Soc 2004;67:476-9.

13. Lee JH, Kwon KH, Kim YB. Deflation of saline filled breast implant by scar tissue contracture. J Korean Soc Aesthetic Plast Surg 2002;8:16-8.

14. Macadam SA, Ho AL, Lennox PA, et al. Patient-reported satisfaction and health-related quality of life following breast reconstruction: a comparison of shaped cohesive gel and round cohesive gel implant recipients. Plast Reconstr Surg 2013;131:431-41.

15. Spear SL, Jespersen MR. Breast implants: saline or silicone? Aesthet Surg J 2010;30:557-70.

16. Gutowski KA, Mesna GT, Cunningham BL. Saline-filled breast implants: a Plastic Surgery Educational Foundation multicenter outcomes study. Plast Reconstr Surg 1997;100:1019-27.

17. Cunningham BL, Lokeh A, Gutowski KA. Saline-filled breast implant safety and efficacy: a multicenter retrospective review. Plast Reconstr Surg 2000;105:2143-9.

18. Walker PS, Walls B, Murphy DK. Natrelle saline-filled breast implants: a prospective 10-year study. Aesthet Surg J 2009;29:19-25.

19. Van Slyke AC, Carr M, Carr NJ. Not all breast implants are equal: a 13year review of implant longevity and reasons for explantation. Plast Reconstr Surg 2018;142:281e-289e. 